\title{
Photogrammetric Surface Analysis of Ablation Processes in High-Enthalpy Air Plasma Flow
}

\author{
Stefan Loehle* and Tina Staebler $\ddagger$ \\ University of Stuttgart, D-70569 Stuttgart, Germany \\ Thomas Reimer \\ DLR, German Aerospace Center, D-70569 Stuttgart, Germany \\ and \\ Alessandro Cefalu§ \\ University of Stuttgart, D-70174 Stuttgart, Germany \\ DOI: $10.2514 / 1 . J 053728$
}

\begin{abstract}
Results from an in situ analysis of ablative heat shield materials based on stereoscopic photogrammetry during plasma wind tunnel testing are presented. A carbon fiber preform material sample has been investigated in a highenthalpy airflow corresponding to a Hayabusa reentry condition at a $78 \mathrm{~km}$ altitude. The applied photogrammetry uses two digital single lens reflex cameras triggered at 3 frames/s to acquire images simultaneously from two different perspectives of the sample exposed to the high-speed flow. The photogrammetric analysis resolves the surface with $25,000 \mathrm{px} / \mathrm{cm}^{2}$, approximately $400 \mathrm{dpi}$, allowing the in situ analysis of the recession phenomena of ablators. Material inhomogeneities are identified during the ablation process, and surface recession is derived with an accuracy of $21 \mu \mathrm{m}$. The method is a useful tool for the investigation of temporally resolved volumetric ablation phenomena in low-density carbon phenolic materials.
\end{abstract}

\section{Introduction}

$\mathbf{E}$ XPERIMENTAL investigation of the thermochemical performance of heat shield materials is usually conducted in so-called plasma wind tunnels [1,2]. The state-of-the-art diagnostic tools to judge the performance of the material during testing are based on the measurement of surface temperatures, in-depth temperatures using thermocouples, and spectroscopic diagnostics in order to investigate the plasma layer in front of the tested materials [3,4]. Classically, the performance of a char layer is described by the recession velocity assuming a steady-state process at the surface. For the measurement of the material's recession in ground testing, the common approach is to compare the sample thickness before and after the test; however, this method does not give insight into transient processes that may be occurring. Experimental methods to assess the surface state during testing are missing. Furthermore, an in situ surface structure analysis is not possible from this measurement.

In modern lightweight ablators, recession generally occurs as a volumetric process in a layer of the material close to the surface; i.e., the ablation can occur in depth [5]. Low-density ablators consist of a highly porous carbon preform. The pores are then filled with a phenolic resin. When the temperature increases, this virgin material decomposes and is destroyed. The main processes occurring are pyrolysis and ablation. Pyrolysis is the transfomation of the phenolic resin into a gas to a low-density carbon or a charred material. The material loses a major part of its mass through this process (on the order of 50\%). The

Presented as Paper 2014-2248 at the 11th AIAA/ASME Joint Thermophysics and Heat Transfer Conference, Atlanta, GA, 16-20 June 2014; received 28 June 2014; revision received 4 March 2015; accepted for publication 20 May 2015; published online 28 September 2015. Copyright $(\odot$ 2015 by the authors. Published by the American Institute of Aeronautics and Astronautics, Inc., with permission. Copies of this paper may be made for personal or internal use, on condition that the copier pay the $\$ 10.00$ per-copy fee to the Copyright Clearance Center, Inc., 222 Rosewood Drive, Danvers, MA 01923; include the code 1533-385X/15 and \$10.00 in correspondence with the CCC.

*Research Scientist, Institute of Space Systems, Pfaffenwaldring 31. Member AIAA.

†Master's Student, Institute of Space Systems, Pfaffenwaldring 31

${ }^{\ddagger}$ Research Scientist, Institute of Structures and Design, Pfaffenwaldring 3840. Member AIAA.

${ }^{\S}$ Research Scientist, Institute of Photogrammetry, Geschwister-SchollStrasse. 24d. gases emerging during this process are injected into the boundary layer, and this process is one important feature of how ablative heat shields function. The carbonaceous material is exposed to oxidation and nitridation with the gas, sublimation (at high temperatures), and eventually mechanical thermochemical surface erosion. The significance of nitridation for recession has been shown to be rather low [6]. Sublimation, i.e., the phase change to gas of the carbon solid (char and fibers), becomes significant at high temperatures above $3000 \mathrm{~K}[5,7]$. However, mechanical erosion can be important depending on the surface state and surface layer porosity.

Therefore, ground testing methodologies need to be extended to enable a better understanding of these processes in ground test facilities. This paper presents a method for the in situ analysis of the surface state during testing using stereoscopic photogrammetry.

In-flight surface recession can only be determined using embedded sensors and sophisticated analysis tools. One of the recent developments is the recession sensor developed for the Mars Science Laboratory [요의. In ground testing environments, however, the surface can be observed using optical methods. Very simple approaches are based on the observation of laser spots on the surface, which change position when the material changes [10].

The approach followed in the present work is the direct observation of the surface from different perspectives and the application of photogrammetric tools in order to determine the three-dimensional surface geometry. This technology has been successfully demonstrated by Schairer and Heineck [11] for arcjet tests at NASA Ames Research Center using charged-coupled device video cameras [11]. This system acquired images at a maximum frame rate of $16 \mathrm{~Hz}$ and resulting in a displacement uncertainty of $0.2 \mathrm{~mm}$ for a stagnation model and $0.3 \mathrm{~mm}$ for a panel model.

In this paper, stereoscopic photogrammetry using two photo cameras, a combination of open source software tools, and commercial programs have been used to analyze simultaneously acquired photographs of the recessing surface. Modern photogrammetric software tools are based on a pixelwise analysis, allowing a high geometrical resolution and a comparably high accuracy. Two digital single lens reflex (DSLR) cameras were adapted for plasma wind tunnel purposes using fixed focal length $(300 \mathrm{~mm})$ lenses.

The method was tested using a carbon preform material (Calcarb). Its surface was assumed to be comparable to a low-density carbon ablator surface. Within the present study, experimental results are presented from an in situ surface analysis of these material probe surfaces using photogrammetric analysis. 


\section{Experimental Setup}

The material tests within this study were conducted in the plasma wind tunnel plasma wind tunnel 1 (PWK1) at Institut fuer Raumfahrtsysteme (IRS). A direct view onto the sample surface mounted in the probe inside the vacuum vessel for the photogrammetric system was provided through optical windows in the front lid. The probe was mounted on a moving platform inside the vacuum chamber.

The vacuum chamber ( $6 \mathrm{~m}$ in length and $2 \mathrm{~m}$ in diameter) was connected to the in-house vacuum pumping system. The generator RD5, a magnetoplasmadynamic arcjet [12], was mounted in the front lid of the vessel. A current-regulated thyristor rectifier consisting of six identical units supplying $1 \mathrm{MW}$ each provided electric power. Samples and measurement equipment were mounted in corresponding water-cooled probes. The probes were moved axially inside the chamber to adjust the heat load and total pressure. To increase the number of measurements possible during each experiment, some probes were manufactured with two heads so that two tests could be performed within one experiment by rotating the probe. The present investigation was conducted with a probe that is usually used for the material investigation of ablative test materials $[7,13]$. The sample used was a carbon preform of type Calcarb with a probe diameter of $40 \mathrm{~mm}$. This material has also been considered suitable in other facilities for fundamental ablation testing [14]. Figure 1 shows a photo of the probe as mounted in the sample holder. Originally, this probe setup was designed for testing samples equipped with thermocouples. The outer, water-cooled copper ring allowed the integration of thermocouples in the sample, which were mounted in parallel to the surface, i.e., along the isotherm of the heated sample. With this setup, a more accurate temperature measurement has been tried.

A flow condition that was developed for a ground test analysis of the observed Hayabusa reentry in 2010 has been chosen $[15,16]$. This flow condition is also part of a research project funded by the ESA led by École Federale Polytechnique de Lausanne [17]. The images presented in this paper were acquired during experiments performed for this ESA project.

The parameters of the chosen flow condition are summarized in Table 1 . Heat flux and total pressure were measured in separate tests using the same probe geometry. Heat flux was derived from a calorimetric cold wall heat flux measurement on a preoxidized copper surface. A copper insert of the size of a material sample was integrated in the sample holder as seen in Fig. 1. This copper sample was cooled with a separate cooling circuit. By measuring the water cooling flow rate and the temperature difference between water inlet and outlet, the heat flux at the surface was determined. The massspecific enthalpy was calculated with the approximation of Zoby [18] from the one-dimensional stagnation point heat transfer equations developed by Fay and Riddell [19]. The measured cold-wall heat flux on the preoxidized surface is assumed to be the fully catalytic surface

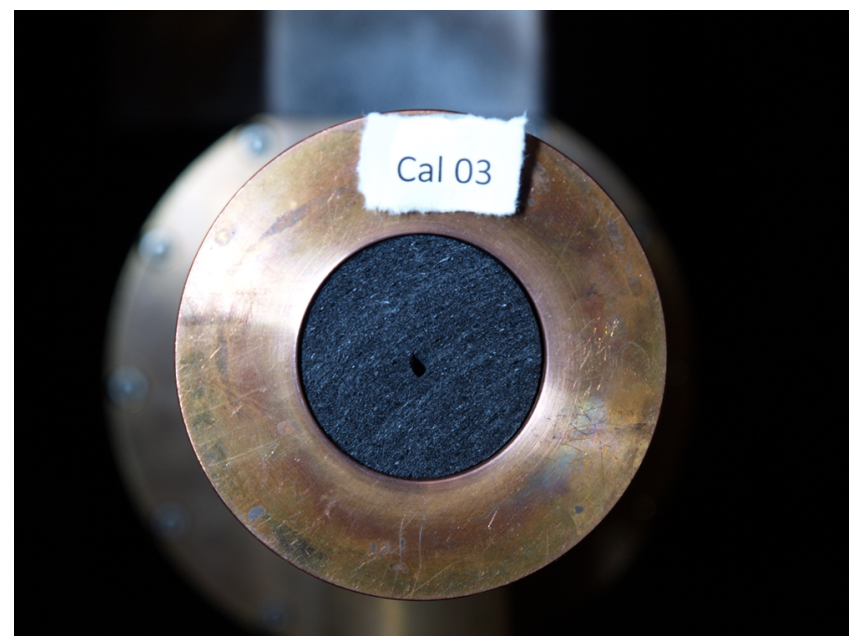

Fig. 1 Material probe holder with mounted Calcarb probe.
Table 1 Plasma wind tunnel condition for the condition corresponding to Hayabusa at $78.8 \mathrm{~km}$

\begin{tabular}{lc}
\hline \hline Parameter & Value \\
\hline Mass flow $\dot{m}$ & $18.0 \mathrm{~g} / \mathrm{s}$ \\
Ambient pressure $p_{\infty}$ & $16.6 \mathrm{hPa}$ \\
Total pressure $p_{\text {tot }}$ & $24.3 \mathrm{hPa}$ \\
Arc current $I$ & $1220 \mathrm{~A}$ \\
Arc voltage $U$ & $133 \mathrm{~V}$ \\
Electric power $P$ & $162 \mathrm{~kW}$ \\
Probe position & $x=270 \mathrm{~mm}, y=0 \mathrm{~mm}$ \\
Heat flux $\dot{Q}$ & $4100 \mathrm{~kW} / \mathrm{m}^{2}$ \\
Mass-specific enthalpy $h$ & $68.43 \mathrm{MJ} / \mathrm{kg}$ \\
\hline \hline
\end{tabular}

heat flux that is required for the application of the approximation of Zoby [20].

There were only small optical windows through which to observe the plasma flow and the probe. Figure 2 shows a photograph and a schematic of the setup using two cameras. The best solution for photogrammetry is to use the two angled windows in the front lid of the vacuum chamber. Here, possible reflectivity issues were minimized, and a comparably long path along the axial direction of the wind tunnel could be observed. The front lid had to be opened for sample installation; therefore, the cameras were mounted on separate tripods with sufficient distances to the facility. This had the further advantage that vibrations of the vacuum chamber during the vacuum pumping startup did not affect the camera setup. A possible influence of the windows with respect to the photogrammetric measurements was analyzed during the previous work [21]. In this configuration, the angle between the imaging axis of the two cameras was between 95 and $100 \mathrm{deg}$. Depending on other instruments used in the experiment, the distance between the probe and camera varied between 2.8 and $4.0 \mathrm{~m}$. A nearer position is preferable, but was restricted by the space required to open the front lid of the vacuum vessel.

The images were acquired using two Canon EOS 60D DSLR cameras. Two prime lenses with $300 \mathrm{~mm}$ focal length (Canon EF $300 \mathrm{~mm} \mathrm{1/4L} \mathrm{IS} \mathrm{USM)} \mathrm{were} \mathrm{used} \mathrm{with} \mathrm{the} \mathrm{cameras.} \mathrm{Table} 2$ lists the parameters of the camera setup. The cameras were triggered simultaneously within $<100 \mathrm{~ms}$ of each other using a radio controlled trigger. For the present analysis, a frame rate of 3 frames/s was achieved. The high luminosity of the probe required the use of a neutral density filter with an optical density of 1.2. This filter transmitted only $6.3 \%$ of the incident light.

A further important parameter of the measurements presented here is the surface temperature. Surface temperature was measured using a linear pyrometer (LP3 from KE Technologies GmbH). The pyrometer used a silicon-based detector calibrated against the ITS-90 standard. Measured temperatures have an uncertainty of $<2 \%$. The measurement wavelength was $950 \mathrm{~nm}$, and the system focused on a single spot with a diameter of $\approx 5 \mathrm{~mm}$. The temperature was corrected for window transmission (measured Suprasil window transmission $\tau_{\text {Window }}=0.92$ ) and surface emissivity (carbon value for emissivity assumed $\epsilon=0.85$ ).

\section{Theory}

The general term "photogrammetry" is the estimative method to determine the position of a point in space using two or more (twodimensional) images of the scene under different view angles. "Stereophotogrammetry," as used in this study, is understood as the calculation of the three-dimensional coordinates of points of a structure using only two views under two different view angles. As described before, two DSLR cameras were used through two windows in the front lid of the plasma wind tunnel in order to observe the probe surface from two perspectives.

Three steps were required to analyze the images using three different software packages:

1) The first step was the calibration of the measurement of the position and orientation of the system. This was done with the software Agisoft PhotoScan. The output was a set of calibration parameters. 

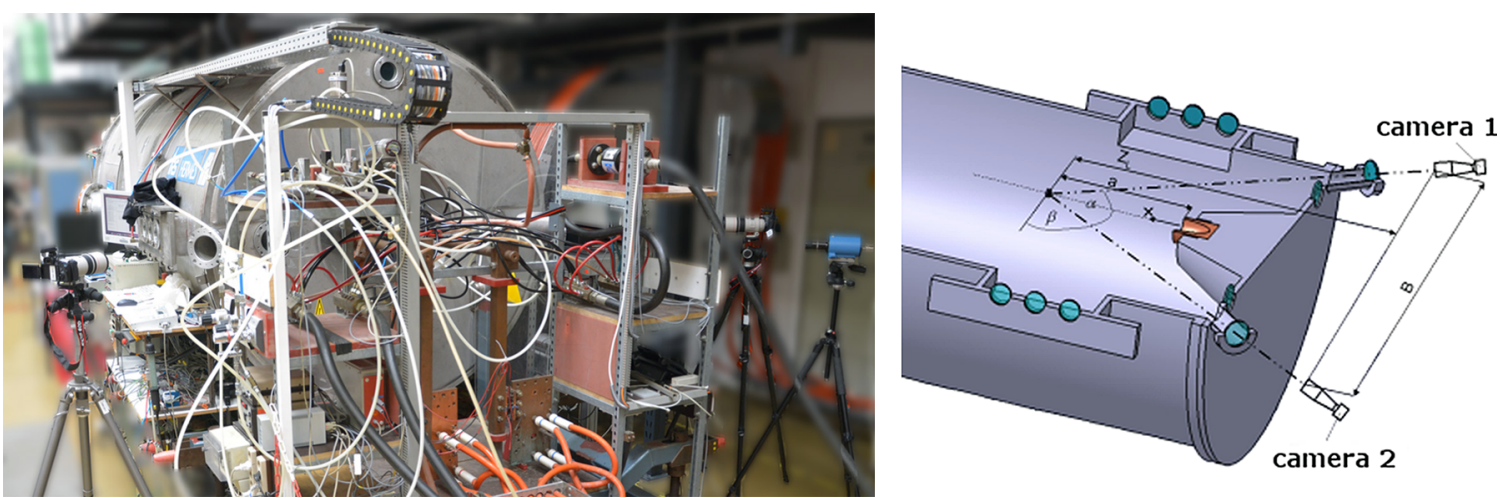

Fig. 2 Plasma wind tunnel PWK1 (left) and geometrical setup for the photogrammetry (right).

2) The next step was measurement. The calibration parameters were applied to analyze the measured image pairs. This analysis was done using the software Sure. The output was a point cloud.

3 ) The third step was recession and surface analysis. The point clouds were loaded into the software CloudCompare.

The first analysis step was conducted with Agisoft PhotoScan, a commercial software [22]. The software was used to calculate the inner and outer orientations of the camera setup by using a separate set of images dedicated to the calibration.

This calibration was conducted with a generic three-dimensionally structured image (see Fig. 3).

Using a structured surface with varying rectangles was best for a high-calibration accuracy. The scale on the calibration plate was used for metric scaling. The calibration procedure was as follows: The cameras were set up at the wind tunnel and focused to the probe position. Then, the calibration plate was mounted at this (the probe's) position. The calibration images were captured by rotating and tilting the plate, following a photogrammetric standard calibration scheme [23]. These images were required to calculate the cameras' positions with respect to each other and the cameras' sensor imaging geometries. These are called the outer and inner orientations, respectively.

The calibration images were loaded in PhotoScan and assigned to the camera by which they were taken (left image: left camera; right image: right camera). Image data (e.g., focus length) were automatically obtained from the image's exchangeable image file format data. If the calibration plate did not fully cover each image, masks were added or images were removed. First, PhotoScan calculated the approximated values for all unknowns (see Table 3 ) using a structurefrom-motion approach [24].

Here, point features in the images were automatically detected and described. The descriptors were used to find correspondences between images, and therefore a sufficiently textured calibration plate was required. In a second step, the results were refined by bundle adjustment. It used the so-called collinearity equations [Eqs. (1) and (2)], i.e., the mathematical description of the central perspective relation between a point $P$ in three-dimensional space and its two-dimensional projection onto the camera's image plane $P^{\prime}$ (see Fig. 4) [25]:

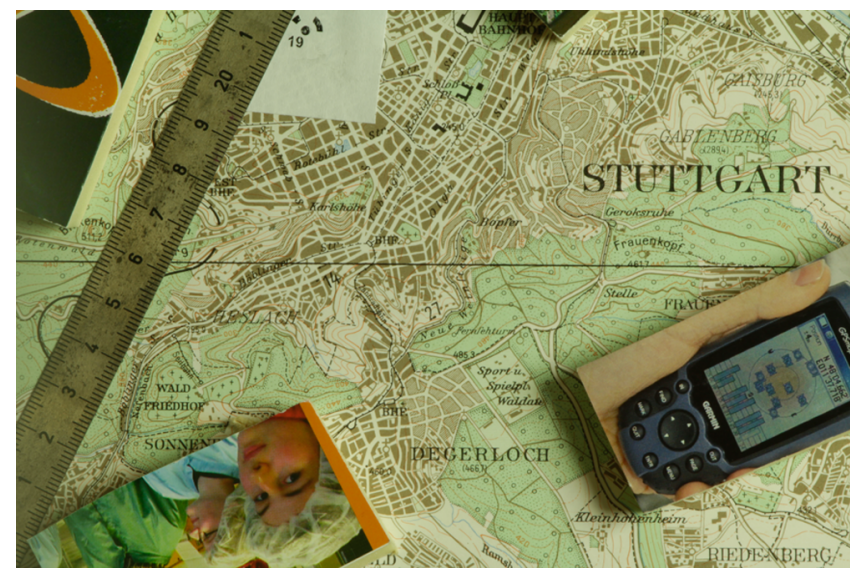

Fig. 3 Structured calibration plate.

$$
\begin{aligned}
& x=x_{0}+f \frac{r_{11}\left(X-X_{0}\right)+r_{21}\left(Y-Y_{0}\right)+r_{31}\left(Z-Z_{0}\right)}{r_{13}\left(x-X_{0}\right)+r_{23}\left(Y-Y_{0}\right)+r_{33}\left(Z-Z_{0}\right)}+\Delta x \\
& y=y_{0}+f \frac{r_{12}\left(X-X_{0}\right)+r_{22}\left(Y-Y_{0}\right)+r_{32}\left(Z-Z_{0}\right)}{r_{13}\left(x-X_{0}\right)+r_{23}\left(Y-Y_{0}\right)+r_{33}\left(Z-Z_{0}\right)}+\Delta y
\end{aligned}
$$

Within the adjustment, the model was further extended through additional lens distortion polynomials.

As mentioned, the results of this calibration are the calculation of the inner orientation of the cameras, i.e., the chip orientation, and the outer orientation, i.e., the position of the cameras with respect to each other. Figure 5 shows the result of the calibration process: The calibration plate was tilted and turned and with both cameras, and images were taken. Then, the three-dimensional point map of the calibration plate was calculated. In the figure, the representation was virtually inverted; the calibration plate was centered and fixed in space, and the camera poitions of the calibrations were positioned.

Table 3 Photogrammetric parameters

Table 2 Camera setup

\begin{tabular}{lc}
\hline \hline Camera & Canon EOS 60 D \\
\hline Pixel resolution & $5184 \times 3456 \mathrm{pixel}^{2}$ \\
Chip size & $22.3 \times 14.9 \mathrm{~mm}^{2}$ \\
Pixel size & $4.3 \mu \mathrm{m}$ \\
Aperture & 25 \\
ISO & 100 \\
Exposure & $1 / 4000 \mathrm{~s}$ \\
Focal length & $300 \mathrm{~mm}$ \\
Color depth & $24 \mathrm{bits}$ \\
Neutral density filter & $\mathrm{ND} 1.2$ \\
Frame rate & 3 frames/s \\
Image format & Joint photographic expert group \\
\hline \hline
\end{tabular}

\begin{tabular}{ll}
\hline \hline Variable & Description \\
\hline Observed & \\
$P^{\prime}(x, y)$ & Image coordinates of a measured point \\
Unknown inner orientation & Focal length \\
$f$ & Principal point (intersection of image \\
$x_{0}, y_{0}$ & plain and optical main axis) \\
Unknown outer orientation & Rotation matrix (three camera \\
$R$ & orientation angles), $r_{i, j} \rightarrow$ single entries \\
O(X, $\left.X_{0}, Z_{0}\right)$ & Translation vector (camera position) \\
Unknown three-dimensional points & \\
$P(X, Y, Z)$ & Point coordinates in a reference system \\
\hline \hline
\end{tabular}




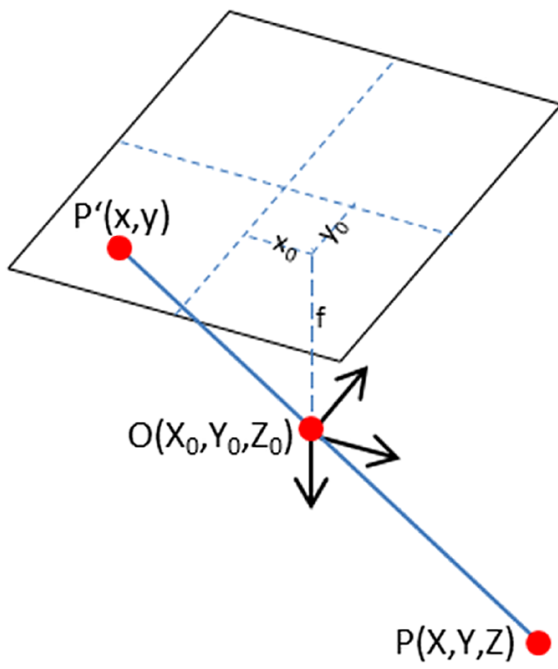

Fig. 4 Photogrammetric nomenclature; angles of rotation and the reference coordinate system are not shown for better visualization.

The camera positions with respect to each other, however, were fixed. Every square in Fig. $\underline{5}$ is a different camera position. The acquisition, however, was made by a steady camera and a tilted and rotated calibration plate. Since the distance between camera and calibration plate was not changed during calibration, the square images in Fig. $\underline{5}$ are aligned approximately on a half-sphere. The zooming indicated by the circles shows closeups of the point cloud determined from the calibration.

A scale was added in PhotoScan using markers that were automatically assigned to the three-dimensional model. Finally, one single stereo image pair with high accuracy and good contrast was selected, and its camera orientation was exported to a project file. As the orientation of the cameras relative to each other qA constant during calibration and testing, the orientation could be used for all image pairs taken during the wind tunnel test.

The analysis of this acquired data set was based on the software Sure, which is a computer code developed by the Institute of Photogrammetry at the University of Stuttgart [26]. The program calculated a point cloud using dense matching algorithms based on the epipolar geometry from the calibration. The wind tunnel testing images were cropped to the region of interest, and the parameters in the orientation file were changed to the new image dimensions and the adapted coordinates of the principal point.

The orientation files calculated with PhotoScan were used in Sure for the plasma wind tunnel image analysis. In a first step, Sure rectified the loaded image pair, and then corresponding points in the two images were identified and calculated. During analysis, the depth information of the points was dynamically used and compared along epipolar lines (Fig. 6). Thanks to the calibration, the camera positions with respect to each other are known. Therefore, a certain point of the object seen on the camera image in one camera lay on the epipolar line on the image of the other camera. The epipolar line was not necessarily a straight line nor was it horizontal in the images. Features in one image could be found on the line in the other image so that the algorithm could reconstruct the object's three-dimensional form. Within this work, the geometrical distortions have been corrected in PhotoScan. Then, the epipolar lines were horizontal lines on one pixel line, simplifying the further analysis (see the lower right of Fig. 6).

The result from this calculation step is a three-dimensional point cloud of the sample surface. The procedure was repeated for every image pair, resulting in 90 three-dimensional probe surface point clouds. These clouds were then loaded in CloudCompare, an open source software project for visualization. The edges of the probe usually could only be seen by one camera, leading to calculation artifacts. Therefore, these parts were cut off. Afterwards, meshes were generated with the Delaunay triangulation for each point cloud. Each mesh was a surface topography at a distinct time. With this information, the distances between meshes, temporal evolution of

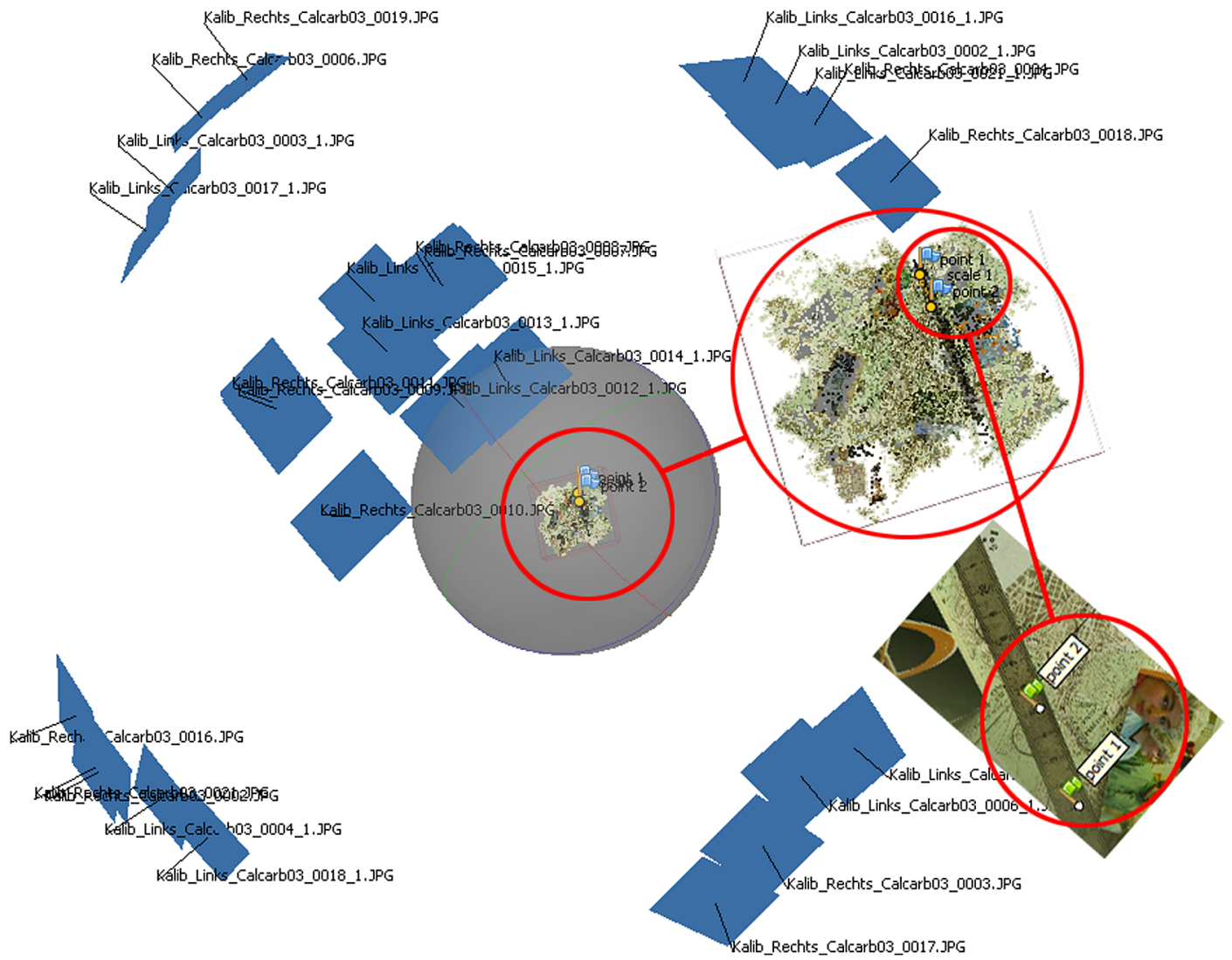

Fig. 5 Three dimensional point map with camera positions and scale. Each square corresponds to one cliabration image. 

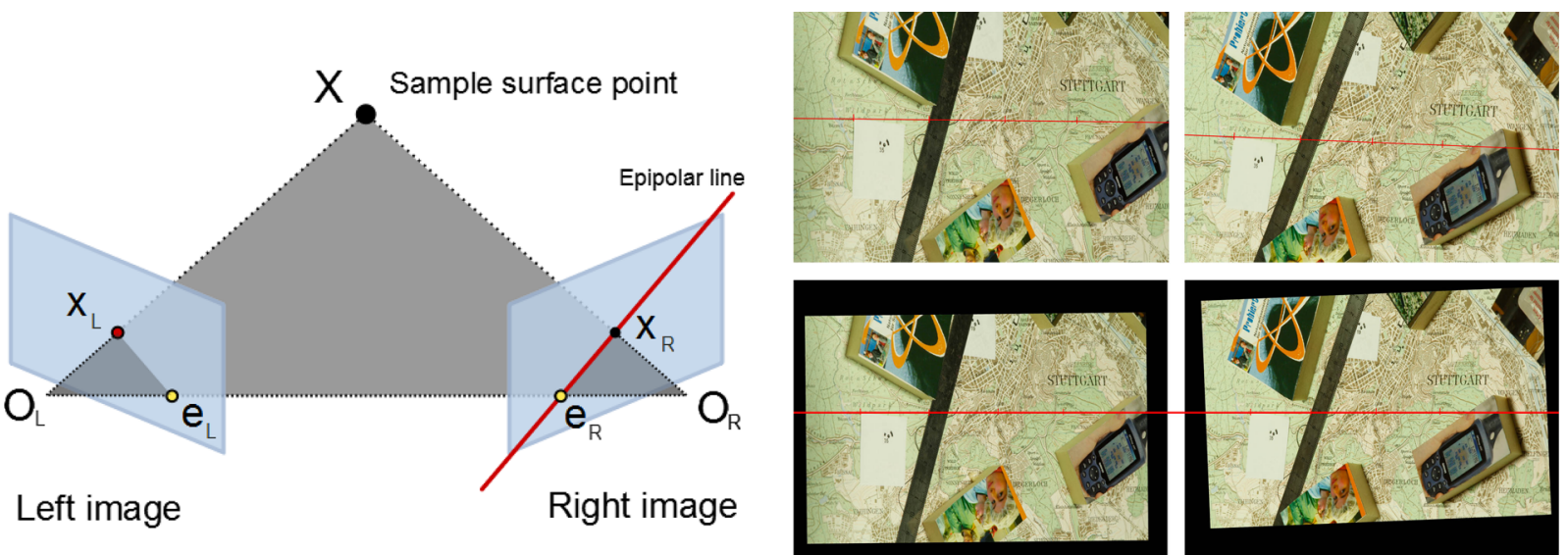

Fig. 6 Definition of the epipolar line (left) and sample epipolar lines in calibration image pairs (right).

certain probe surface features, and local surface recession were analyzed.

The whole system was qualified and characterized with a sample mounted on a measuring table. The sample was moved on this table by a very accurately known defined distance. The photogrammetric setup was positioned as it was realized on the wind tunnel. The movement was recalculated by the photogrammetric setup. The rebuilding accuracy between the defined step and the photogrammetric result is below $1.7 \%$.

\section{Results}

Figure 7 shows an image of the probe during testing in the hot plasma flow. The bright plasma emission in the optical wavelength range was reduced by the cameras through the short exposure time $(1 / 4000 \mathrm{~s})$ and the additional neutral density (ND) filter. During the startup of the plasma generator, the sample was positioned outside the plasma jet. When the conditions were set, the sample was moved into the flow to the defined position. As mentioned, the left and the right camera were simultaneously acquiring images during test. The start time for the following analysis $(t=0 \mathrm{~s})$ was set to the moment when the sample had reached the position on the center axis of the flow and was seen by both cameras at the calibrated location. For the measurements in this study, a frame rate of 3 frames/s was chosen. During the plasma wind tunnel experiment, the cameras automatically acquired images. For a typical $30 \mathrm{~s}$ test, there was a total of 90 image pairs. Every image pair corresponded to a particular time during the testing. It was a tradeoff between the camera performance, data acquisition, and data handling for the photogrammetry. As an example, Fig. $\underline{8}$ shows the cropped photographs taken at one instant in time at the beginning of the testing when the probe was in position. The darker spot in the center of the sample is a bore used for spectroscopic measurements, which were ongoing in parallel $[27,28]$. The two straight darker lines in the upper

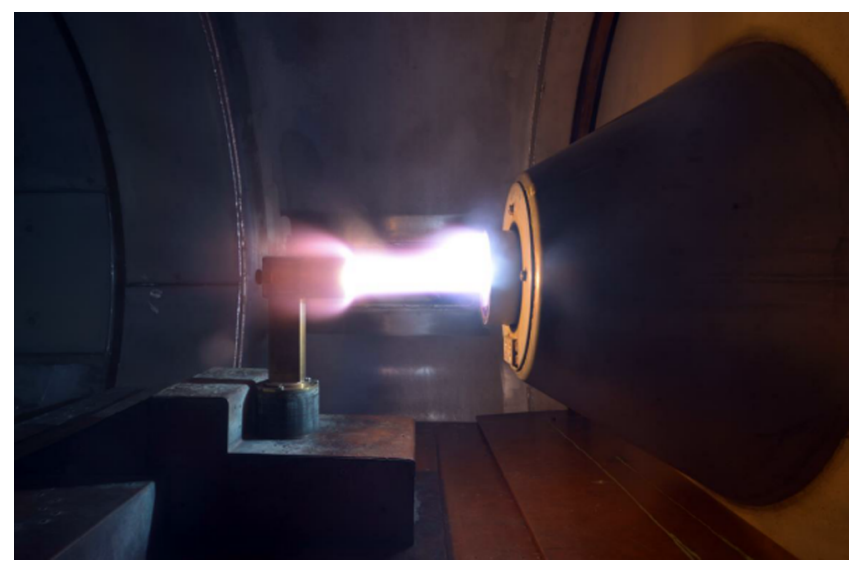

Fig. 7 Side view of the probe during experiment. left corner of the sample were identified as indentations in the surface. In total, 96 image pairs were acquired. The dimensions of the cropped photos were $1049 \times 1562 \mathrm{px}^{2}$. In the following analysis, different image pairs are compared in order to derive the surface recession and the corresponding recession rates.

In Fig. 9, exemplarily, eight different surface reconstructions at different instants of time during testing are shown. The surface was measured with $25,000 \mathrm{px} / \mathrm{cm}^{2}$, corresponding to about $400 \mathrm{dpi}$. The plots show the surface where the gray scale is the depth in millimeters from the state of the beginning of the test $(t=0 \mathrm{~s})$ until the time of acquisition. So, the last image $(t=32 \mathrm{~s})$ shows the recession after $32 \mathrm{~s}$. The present investigation allows, for the first time, conclusions to be drawn about behavior of the material surface during testing.

It can be seen that at the beginning the sample surface was quite a flat, slightly roughened surface. During the test, the surface was recessing (larger parts of the surface became darker), and the surface roughness increased. On the right side of each shown frame is a scale with the histogram of the depth distribution with respect to the first frame $(t=0 \mathrm{~s})$. Thus, the peak here is the recession amount of the bulk of the material. The sample surface reconstruction using the photogrammetric setup was limited at the outer edge of the sample. During the testing, the sample's recession led to areas that were no longer seen by one of the cameras, because the sample was offset to the copper ring. Therefore, in the first image, when the sample was flush mounted to the cooled copper holder (see Fig. 1), the whole sample surface was observable by both cameras, and the resulting surface reconstruction was almost circular. With the increasing test time, the sample boundaries became hidden behind the copper, and a surface reconstruction was impossible. Therefore, the sample in the last image did not show a circular outer boundary.
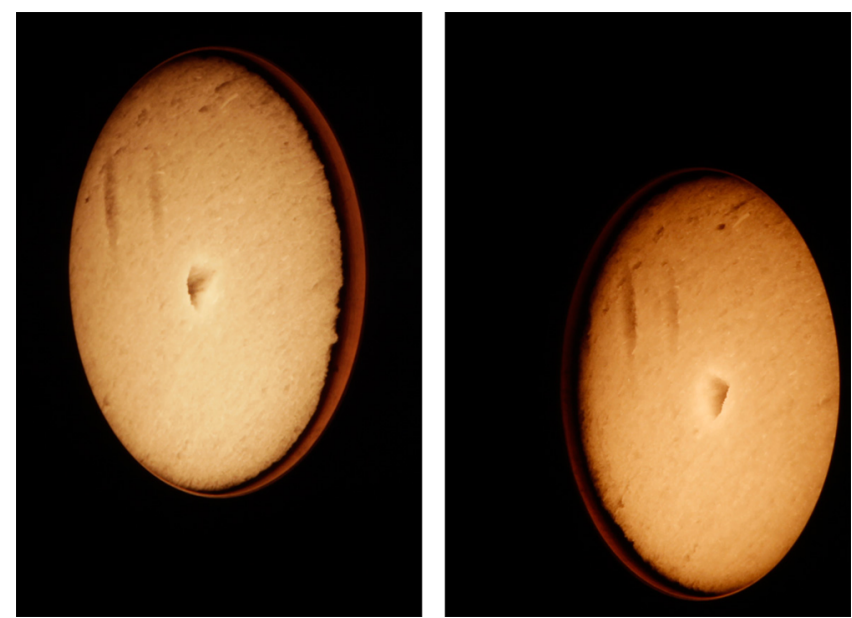

Fig. 8 An example pair of the cropped images (left and right cameras becomes left and right images, respectively). 

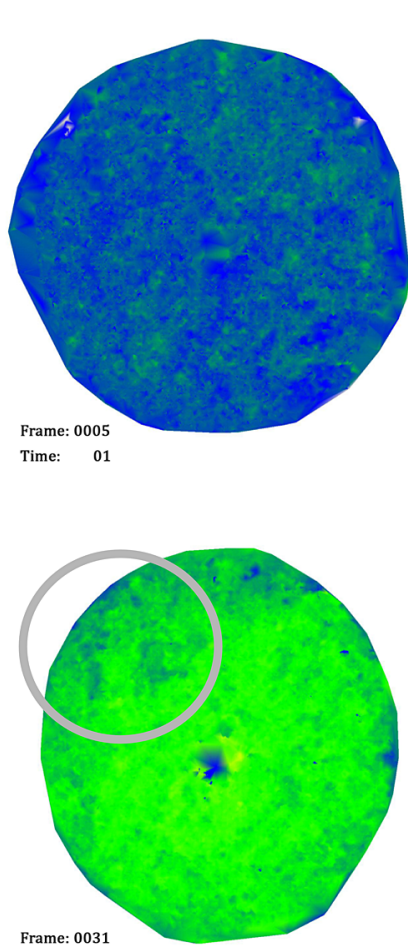

Time: 09

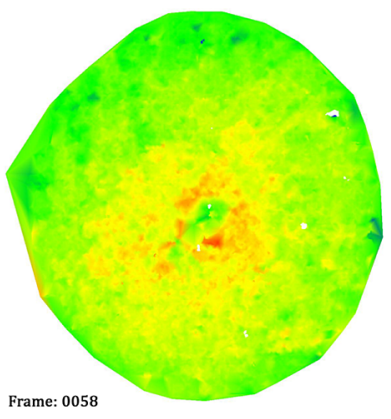

Time: 19

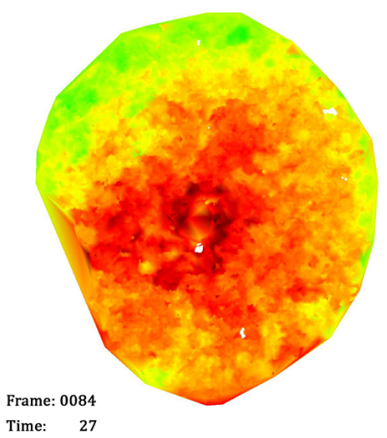

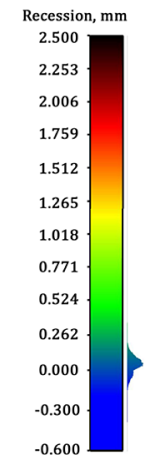

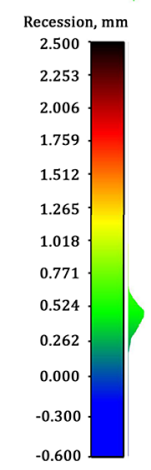

12.5

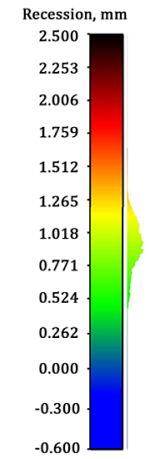

$12.5 \mathrm{~mm}$

Recession, $\mathrm{mm}$

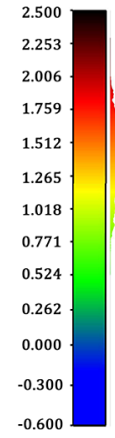

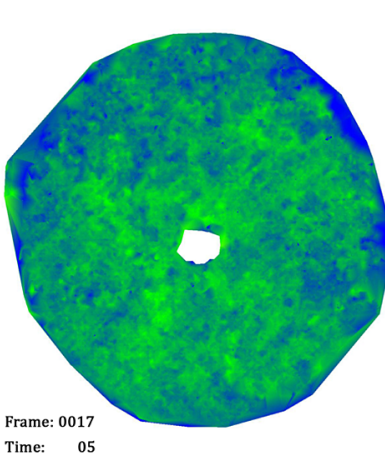
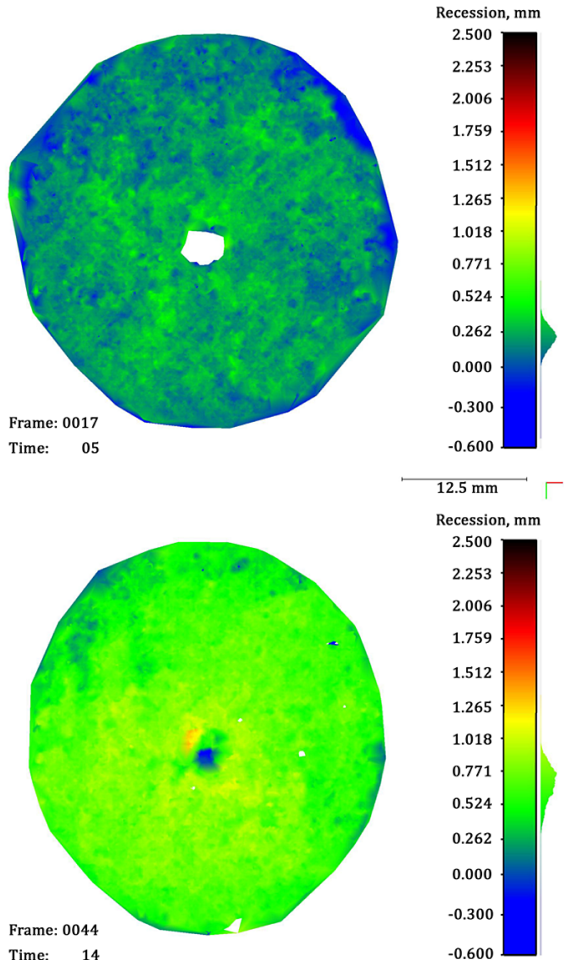

2.500
2.253
2.006
1.759
1.512
1.265
1.018
0.771
0.524
0.262
0.000
-0.300
-0.600

Time: 14

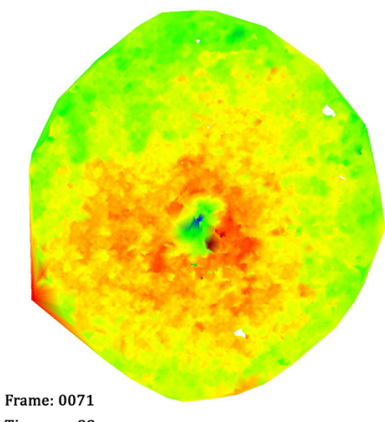

Time: 23

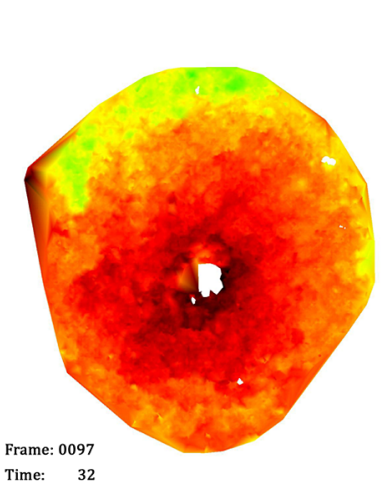

$2.5 \mathrm{~mm}$

Recession, $\mathrm{mm}$

2.500

2.253

2.006

2.006
1.759

1.512

1.265

1.018

0.77

0.524

0.26

0.000

$-0.300$

son

Fig. 9 Exemplary sample surface structure during testing as derived from photogrammetry (time in seconds). The circle marks exemplarily the region of the two scratches (see Fig $\underline{8}$ ).

The region around the centered bore hole recesses more than the outer region of the sample. Surface inhomogeneities, such as the two scratches in the photo of Fig. $\underline{8}$, were seen as well because here the material changed differently from its surrounding regions. The recession rate was calculated from the position of all points in the reconstructed point cloud. Figure 10 shows a histogram of the axial deviation in the recessing direction of the points of frame $19(t=5 \mathrm{~s})$ and the points of frame $27(t=8 \mathrm{~s})$ normalized to $1 \mathrm{~s}$. For each point of the cloud, its recession is plotted in the histogram. On the abscissa, the recession is marked in micrometers/second, and on the ordinate, the quantity of points with the according value are plotted. The histogram is almost a Gaussian distribution (solid line). Its maximum marks the arithmetic mean. The mode, representing the statistical maximum cumulation of a value is not always the same. In the figure, the standard deviation of the Gaussian distribution $(1 \sigma, 2 \sigma)$ is plotted for completion. From this plot, it can be concluded that the mean 


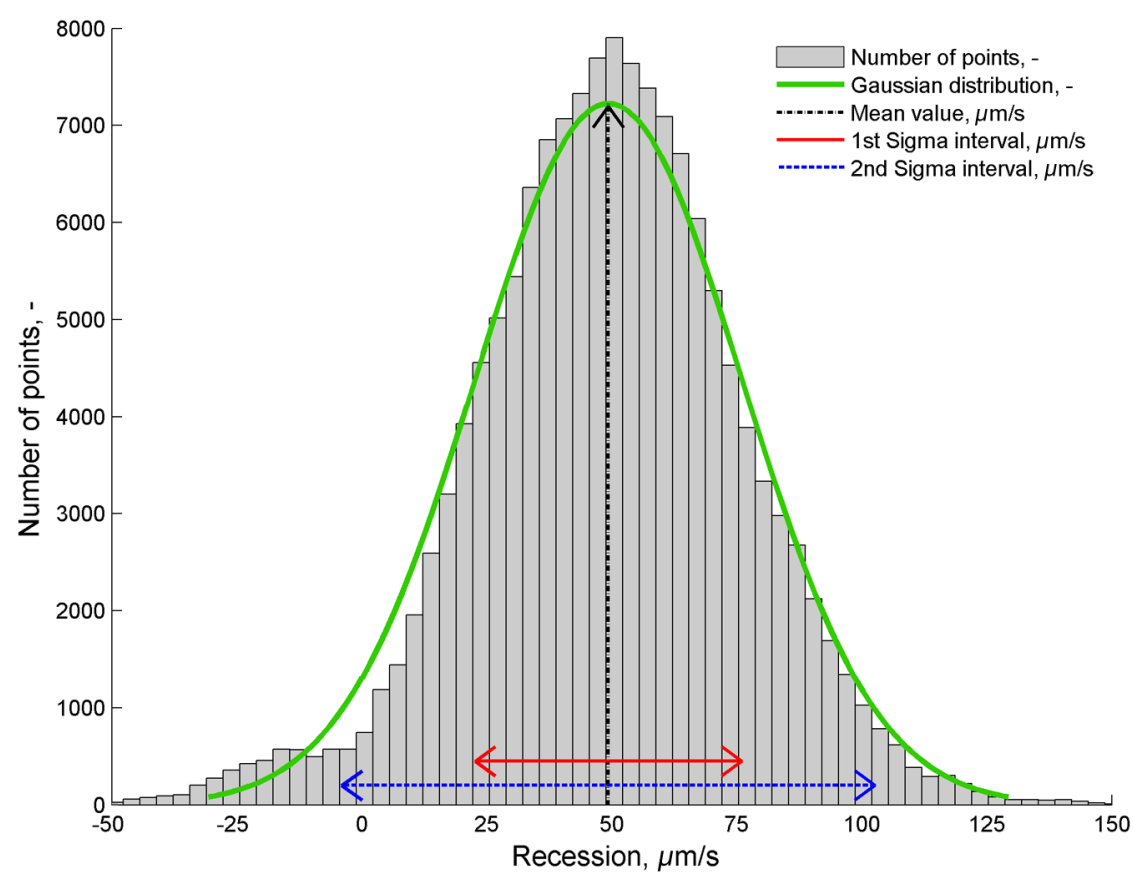

Fig. 10 Histogram of the recession rate over $3 \mathrm{~s}(5$ to $8 \mathrm{~s})$.

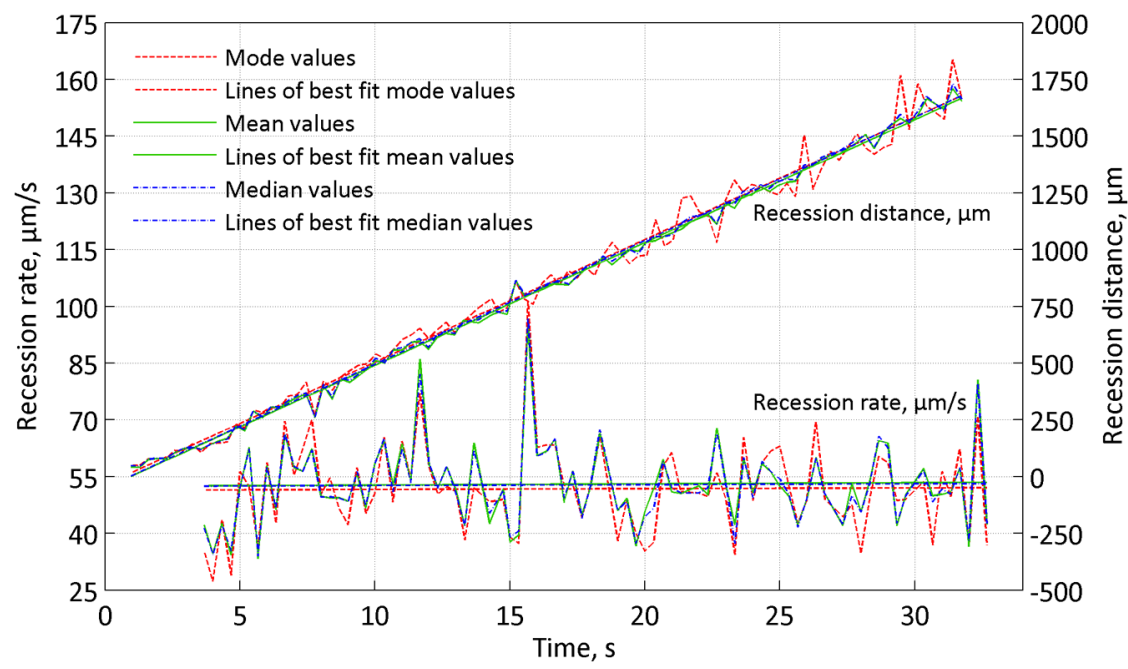

Fig. 11 Recession rate and mass loss.

surface recession rate between $t=5 \mathrm{~s}$ and $t=8 \mathrm{~s}$ was $50 \mu \mathrm{m} / \mathrm{s}$. The recession rate has been calculated for the whole test time, the result of which is plotted in Fig. 11.

Occasionally, and only for short times, a local increase of thickness was observed. The reason for this could be the fiber separation from the material before it was released. As the left side of the histogram in Fig. 10 is declined slightly more steeply than the Gaussian distribution, the arithmetic mean is shifted to a higher value. Comparing 85 histograms during the test results in the values as shown in Table 4. Although the results are very close, the mode value, as a solely statistical value, is more meaningful.

A comparison of mode, mean, and median values during the test duration is shown in Fig. 11. In the lower section, the mass recession rate is plotted, and in the upper section, the recession is plotted. For the mass recession rate, always nine frames ( $3 \mathrm{~s})$ were used to calculate the rate, normalized to $1 \mathrm{~s}$. Therefore, the mass recession rate values started after $3 \mathrm{~s}$.

From this presentation, it can be concluded that the recession rate was very constant over time. Since the sample was a porous carbon preform, an influence of a phenolic matrix as used in modern lightweight ablators was not investigated here.

In Fig. 12, the recession rate during the test time is plotted together with the measured surface temperature. The surface temperature reached a plateau of $2925 \pm 30 \mathrm{~K}$ after a heating phase of about $10 \mathrm{~s}$. From the photogrammetric analysis, an increase in the recession rate from 4 to $7 \mathrm{~s}$ could be interpreted. However, a linear fit gives

$$
y_{\mathrm{rec}}(t)=0.0315 t+52.4349 \mu \mathrm{m} / \mathrm{s}
$$

This rate was very constant; i.e., the recession rate dependence from the surface temperature was weak. The mean recession rate of the sample was measured to $52.5 \mu \mathrm{m} / \mathrm{s}$. 


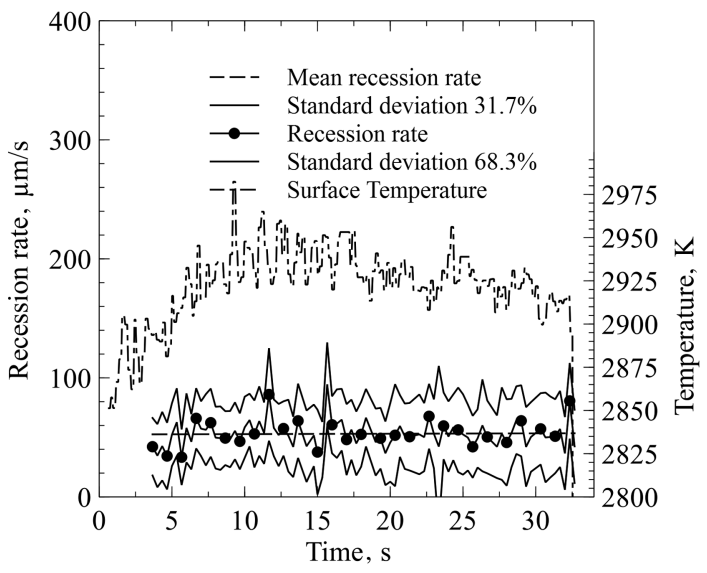

Fig. 12 Recession rate and surface temperature over time.

The standard deviation of the recession increased with time (see Fig. 13); i.e., the mean value of the recession (in micrometers) was more accurate at the beginning of the test than at the end. It was a linear function of the form

$$
y_{\text {sigma }}(t)=0.5407 t+48.5602 \mu \mathrm{m} / \mathrm{s}
$$

As can also be seen from the single images in Fig. 9 , the sample's surface was not recessing homogeneously. Therefore, the standard deviation of the mean value was increasing.

In Fig. 8, there is a lighter circle around the darker bore hole, which is possibly a region of higher temperature and thus higher recession. At sharp corners, heat loads are higher, resulting in more material loss as can be seen in Fig. 14 .

Figure 14 shows the last measured frame at $t=32 \mathrm{~s}$, and Fig. 15 shows a side view of the photogrammetric result. Here, data in the recessing direction are amplified by a factor of 10 for better visualization. The overall recession between the first analyzed frame (frame 4, $t=0 \mathrm{~s}$ ) and the last frame (frame 99, $t=32 \mathrm{~s}$ ) is between $1300 \mu \mathrm{m}$ in the outer circle and $2100 \mu \mathrm{m}$ in the sample center. As the mean mass recession rate is $52.5 \mu \mathrm{m} / \mathrm{s}$, the overall recession is $1.743 \mathrm{~mm}$. The sample thickness was also manually measured before and after testing to $1.74 \mathrm{~mm}$. Despite its high uncertainty, these measured values agree well with the photogrammetry. The inhomogeneity of the recession over the probe surface can have different reasons. First, the material was not isotropic; second, the material holder induced cold outer parts of the probe, leading to less material loss; and third, the plasma flow did not homogeneously cover the

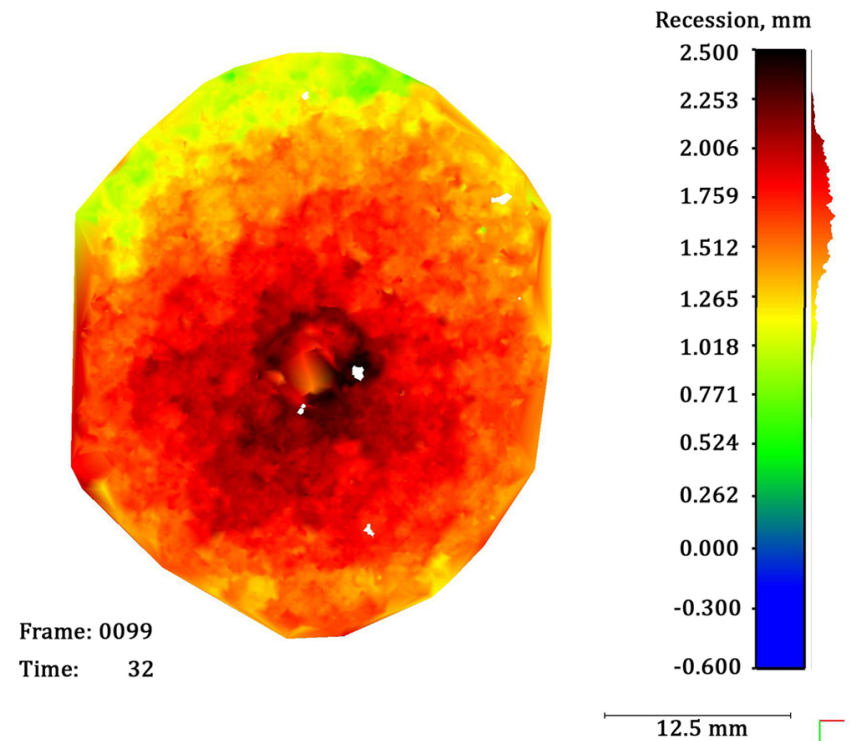

Fig. 14 Surface structure at the end of the test $(t=32 \mathrm{~s})$.
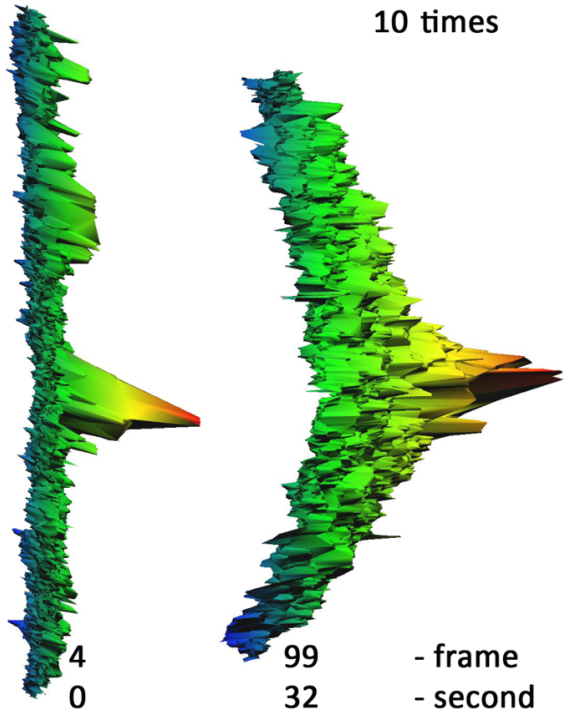

Fig. 15 Side view of surface structure at the beginning $(t=0 \mathrm{~s}$, left $)$ and end of the test $(t=32 \mathrm{~s}$, right).

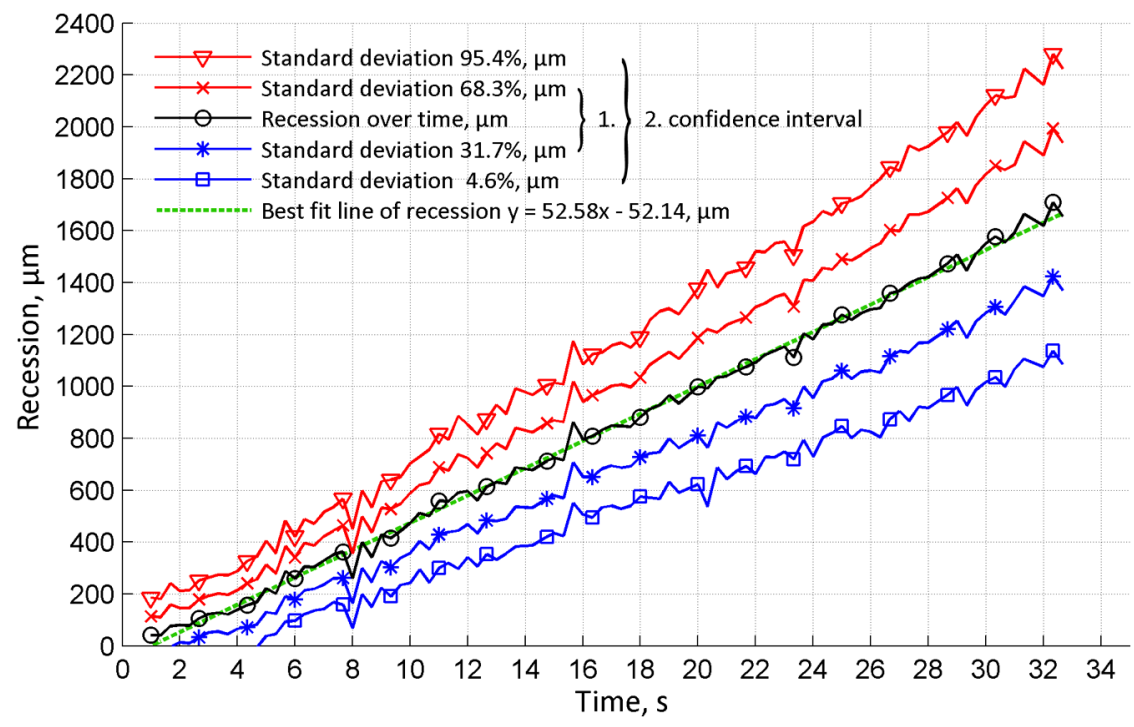

Fig. 13 Recession over time with confidence interval $(1 \sigma, 2 \sigma)$. 
surface. The samples were not equipped with in-depth sensors. Therefore, at this stage, a final conclusion for the higher center recession cannot be given.

Furthermore, the surface roughness increased throughout the test. It is assumed that this was due to the oxidation of the carbon fibers leading to higher porosity and thus a higher surface roughness. Another indicator for this is the anomaly of the two scratches in Fig. 8, which are also seen in this first frame 4 (on the left in Fig. 15). There was less recession at these locations, leading to the conclusion that these features are indentations; i.e., material was pressed here, and thus the oxidation of the carbon was hindered. Their depth as measured from the photogrammetry was $\approx 0.3 \mathrm{~mm}$.

\section{Conclusions}

The stereoscopic photogrammetric analysis of the surface recession in a high-enthalpy air plasma flow allows a very detailed analysis of the ablation process. This work was the first time that this method was applied to study ablative materials. An optical resolution of 25,000 points $/ \mathrm{cm}^{2}$ and a temporal resolution of up to 3 frames $/ \mathrm{s}$ was achieved. The software used was well suited for this application with a reasonable calculation complexity and acceptable computation time. The computing time of the analysis of the experiment, depending on the accuracy and processing power, took between 2 to $6 \mathrm{~h}$. The surface resolution was very high, particularly compared to other methods used hitherto, and allowed for an in situ structural analysis of materials during testing.

\section{Acknowledgments}

The authors gratefully acknowledge the financial support of ESA through the research grant number 2011/ITT-6632/PL. The support of the workshops at the German Research Center and at IRS was very important and is gratefully acknowledged. S. Löhle thanks his colleagues from the High Enthalpy Flow Diagnostics Group for the continuous and prompt help.

\section{References}

[1] Lu, F. K., and Marren, D. E. (eds.), Advanced Hypersonic Test Facilities of Progress in Astronautics and Aeronautics, Vol. 198, AIAA, Reston, VA, 2002, pp. 24-25.

[2] Auweter-Kurtz, M., and Wegmann, T., "Overview of IRS Plasma Wind Tunnel Facilities," NATO, Research and Technology Organization, Educational Note RTO-EN-8, Oct. 1999.

[3] Chen, Y.-K., and Milos, F. S., "Ablation and Thermal Response Program for Spacecraft Heatshield Analysis," Journal of Spacecrafts and Rockets, Vol. 36, No. 3, 1999, pp. 475-483. doi: $10.2514 / 2.3469$

[4] Löhle, S., Eichhorn, C., Steinbeck, A., Lein, S., Herdrich, G., Röser, H.P., and Auweter-Kurtz, M., "Oxygen Plasma Flow Properties Deduced from Laser-Induced Fluorescence and Probe Measurements," Applied Optics, Vol. 47, No. 11, 2008, pp. 1837-1845. doi:10.1364/AO.47.001837

[5] Lachaud, J., Cozmuta, I., and Mansou, N. N., "Multiscale Approach to Ablation Modeling of Phenolic Impregnated Carbon Ablators," Journal of Spacecrafts and Rockets, Vol. 47, No. 6, 2010, pp. 910-921. doi: $10.2514 / 1.42681$

[6] Beerman, A. F., Lewis, M. J., Starkey, R. P., and Cybyk, B. Z., "Significance of Nonequilibrium Surface Interactions in Stardust Return Capsule Ablation Modeling," Journal of Thermophysics and Heat Transfer, Vol. 23, No. 3, 2009, pp. 425-432. doi: $10.2514 / 1.38863$

[7] Eswein, N., Herdrich, G., Fasoulas, S., and Röser, H.-P., "Investigation of Graphite Ablation at IRS," 42nd Thermophysics Conference, AIAA, Reston, VA, 2011.

[8] Santos, J. A., Oishi, T., and Martinez, E. R., "Isotherm Sensor Calibration Program for Mars Science Laboratory Heat Shield Flight Data Analysis," 42nd AIAA Thermophysics Conference, AIAA Paper 2011-3955, 2011.
[9] White, T., Cozmuta, I., Santos, J. A., Laub, B., and Mahzari, M., "Proposed Analysis Process for Mars Science Laboratory Heat Shield Sensor Plug Flight Data," 42nd AIAA Thermophysics Conference, AIAA Paper 2011-3957, 2011.

[10] Sherrouse, P., and Carver, D., "Demonstrated Real-Time Recession Measurements of Flat Materials During Testing in High-Enthalpy Flows," 30th Aerospace Science Meeting and Exhibit, AIAA, Reston, VA, 1992.

[11] Schairer, E. T., and Heineck, J. T., "Photogrammetric Recession Measurements of Ablative Materials in Arcjets," Measurement Science and Technology, Vol. 21, No. 2, 2010. doi:10.1088/0957-0233/21/2/025304

[12] Auweter-Kurtz, M., and Wegmann, T., "Overview of IRS Plasma Wind Tunnel Facilities," NATO, Research and Technology Organization, Educational Note RTO-EN-8, 2000.

[13] Wernitz, R., Eichhorn, C., Herdrich, G., Löhle, S., Fasoulas, S., and Röser, H.-P., "Plasma Wind Tunnel Investigation of European Ablators in Air Using Emission Spectroscopy," 42nd AIAA Thermophysics Conference, AIAA Paper 2011-3761, 2011.

[14] Helber, B., Chazot, O., Magin, T., and Hubin, A., "Ablation of Carbon Preform in the VKI Plasmatron," 43rd Thermophysics Conference, AIAA Paper 2012-2876, 2012.

[15] Loehle, S., and Jenniskens, P., "High Resolution Spectroscopy of the Hayabusa Re-Entry Using a Fabry-Perot Interferometer," Journal of Spacecrafts and Rockets (to be published).

[16] Löhle, S., Brandis, A., Hermann, T., and Peter, J., "Numerical Investigation of the Re-Entry Flight of Hayabusa and Comparison to Flight and Ground Testing Data," 43rd AIAA Thermophysics Conference, AIAA, Reston, VA, 2012.

[17] Leyland, P., McIntyre, T., Sheikh, U., Eichman, T., Zander, F., Morgan, R., Löhle, S., Hermann, T., De Filipis, F., Trifoni, E., and Cillo, G., "VUV Radiation Measurements for Ablation-Radiation Coupling," ESA Radiation of High Temperature Gases Workshop ESA-SP-714, 2012.

[18] Zoby, E. V., "Empirical Stagnation-Point Heat-Transfer Relation in Several Gas Mixtures at High Enthalpy Levels," NASA TN-D-4799, 1968.

[19] Fay, J. A., and Riddell, F. R., "Theory of Stagnation Point Heat Transfer in Dissociated Air," AIAA Journal, Vol. 25, No. 2, 1958, pp. 373-386.

[20] Laux, T., Herdrich, G., and Auweter-Kurtz, M., "Mechanische Sonden für Materialtests und Plasmadiagnostik am IRS," DGLR Jahrestagung 2001, German Soc. for Aeronautics and Astronautics, JT2001-167, 2001.

[21] Pitzer, P., "Einfluss Refraktiver und Reflektiver Elemente auf die Photogrammetrische Kamerakalibrierung," Bachelor's Thesis, Univ. of Stuttgart, Stuttgart, Germany, 2012.

[22] "Agisoft PhotoScan," Software Package, Agisoft LLC, Petersburg, Russia, May 2014, www.agisoft.com [retrieved Jan. 2013].

[23] Wester-Ebbinghaus, W., "Verfahren zur Feldkalibrierung von Photogrammetrischen Aufnahmekammern im Nahbereich," DGK Reihe B 275, 1985.

[24] Snavely, N., Seitz, S. M., and Szeliski, R., "Modeling the World from Internet Photo Collections," International Journal of Computer Vision, Vol. 80, No. 2, 2008, pp. 189-210. doi:10.1007/s11263-007-0107-3

[25] Luhmann, T., Nahbereichsphotogrammetrie: Grundlagen, 3rd ed., Methoden und Anwendungen, Wichmann, Berlin, 2010.

[26] Rothermel, M., Wenzel, K., Fritsch, D., and Haala, N., "SURE: Photogrammetric Surface Reconstruction from Imagery," Proceedings of the LowCost3D Workshop, Berlin, Dec. 2012.

[27] Hermann, T., Zander, F., Fulge, H., Löhle, S., and Fasoulas, S., "Experimental Setup for Vacuum Ultraviolet Spectroscopy for Earth ReEntry Testing," 30th Aerodynamic Measurement Technology and Ground Testing Conference, AIAA, Reston, VA, 2014.

[28] Loehle, S., Hermann, T., Zander, F., Fulge, H., and Marynowski, T., "Ablation Radiation Coupling Investigation in Earth Re-Entry Using Plasma Wind Tunnel Experiments," 30th Aerodynamic Measurement Technology and Ground Testing Conference, AIAA, Reston, VA, 2014.

G. Candler Associate Editor 